\title{
St John Simpson, Andrew Meek. "Small, bright and colourful: observations on the circulation of minor glass objects from Sasanian contexts"
}

\section{Rémy Boucharlat}

\author{
(2) OpenEdition \\ Journals \\ Édition électronique \\ URL : http://journals.openedition.org/abstractairanica/51262 \\ DOI : 10.4000/abstractairanica. 51262 \\ ISBN : 1961-960X \\ ISSN : 1961-960X \\ Éditeur : \\ CNRS (UMR 7528 Mondes iraniens et indiens), Éditions de l'IFRI
}

\section{Référence électronique}

Rémy Boucharlat, « St John Simpson, Andrew Meek. "Small, bright and colourful: observations on the circulation of minor glass objects from Sasanian contexts" », Abstracta Iranica [En ligne], Volume 40-41 | 2019, document 71, mis en ligne le 30 décembre 2019, consulté le 27 avril 2021. URL : http:// journals.openedition.org/abstractairanica/51262; DOI : https://doi.org/10.4000/abstractairanica. 51262

Ce document a été généré automatiquement le 27 avril 2021

Tous droits réservés 


\title{
St John Simpson, Andrew Meek. "Small, bright and colourful: observations on the circulation of minor glass objects from Sasanian contexts"
}

\author{
Rémy Boucharlat
}

\section{RÉFÉRENCE}

St John Simpson, Andrew Meek. "Small, bright and colourful: observations on the circulation of minor glass objects from Sasanian contexts" in Paolo de Vingo (ed.). Le Archeologie di Marilli. Miscellanea di studi in ricordo di Maria Maddalena Negro Ponzi Mancini. Alessandria: Edizioni dell'Orso, 2018, (" Mnème », Documenti, culture, storia del Mediterraneo e dell'Oriente Antico, 12), p. 105-120

Les AA. prennent en compte les objets en verre, autres que les récipients, attestés en Mésopotamie entre le $3^{\mathrm{e}}$ et le $7^{\mathrm{e}} \mathrm{s}$. $\mathrm{d} \mathrm{n}$. è, de manière très large, proposant un corpus très utile. Ils ont rassemblé une vaste collection d'objets très variés, éléments de parure, perles bracelets, boucles d'oreille, bagues, ainsi que les sceaux, épingles, bâtonnets, spatules, fusaïoles, poids, pièces de jeu, incrustations, miroirs de poche (un morceau de verre serti dans un cadre) et même des verres de fenêtre et des tessères de sol. Plusieurs séries sont traitées non pas pour les formes mais pour les techniques de fabrication (perles, fusaïoles). En même temps, es AA. tentent de voir si telle catégorie est une production locale ou une importation. Ainsi rien ne prouve que les tessères de mosaïque trouvées près de Ctésiphon à Aspanabr soient une production locale. Une section de l'article est consacrée aux petits objets (des pièces de jeu) en verre ainsi qu'à deux sceaux du British Museum qui ont été analysés: ils ont été produits avec des 
cendres de végétaux (et non pas avec du natron) mais de deux espèces différentes, sans que l'on puisse déterminer s'ils sont des importations ou des productions locales.

\section{AUTEURS}

\section{RÉMY BOUCHARLAT}

UMR 5133 CNRS-Université de Lyon 